AperTO - Archivio Istituzionale Open Access dell'Università di Torino

\title{
Haplo-identical allografting with post-transplant cyclophosphamide in high-risk patients
}

\section{This is the author's manuscript}

Original Citation:

\section{Availability:}

This version is available http://hdl.handle.net/2318/1681720

since 2018-11-21T12:32:55Z

Published version:

DOI:10.1007/s00277-018-3433-3

Terms of use:

Open Access

Anyone can freely access the full text of works made available as "Open Access". Works made available under a Creative Commons license can be used according to the terms and conditions of said license. Use of all other works requires consent of the right holder (author or publisher) if not exempted from copyright protection by the applicable law. 


\title{
Haplo-identical allografting with post-transplant cyclophosphamide in high-risk patients
}

\author{
LuciaBrunello ${ }^{1,2}$ \& Roberto Passera ${ }^{3}$ \& ChiaraMariaDellacasa ${ }^{1}$ \& LuisaGiaccone ${ }^{1,2}$ \& Ernesta Audisio ${ }^{4}$ \& DarioFerrero $^{2,5}$ \& \\ Stefano D'Ardia ${ }^{4}$ \& Bernardino Allione ${ }^{4}$ \& Semra Aydin ${ }^{4}$ \& Moreno Festuccia ${ }^{1,2}$ \& Giuseppe Lia ${ }^{1,2}$ \& Elena Crisà ${ }^{2,5}$ \& Enrico \\ Maffini $^{1,2}$ \& Sara Butera ${ }^{1,2}$ \& Alessandro Busca ${ }^{1}$ \& Benedetto Bruno ${ }^{1,2}$
}

\begin{abstract}
Haplo-identical transplants (Haplo-Tx) are an important alternative for patients with hematological malignancies who lack a HLA-identical donor. Seventy-one T-replete Haplo-Tx were performed in 70 high-risk patients at our center; 22/ $70(31 \%)$ patients with refractory/relapsed leukemia received sequential salvage therapy (SeqTh) with high-dose chemotherapy followed by Haplo-Tx during the chemotherapy-induced neutropenia. Graft-versus-host disease (GVHD) prophylaxis consisted of post-transplant cyclophosphamide (days +3 and +4 ) with tacrolimus and mycophenolic acid. After a median follow-up of 29.2 months, 3-year overall survival (OS) and event-free survival (EFS) were 43.8 and $40.2 \%$, while 3 -year cumulative incidences (CIs) of non-relapse mortality (NRM) and relapse (RI) were 27 and 33\%. Day 100 and day 400 CI of grade III-IV acute and moderate-severe chronic GVHD were 11 and $15 \%$. Threeyear RI was significantly lower in patients in complete remission (CR) versus those not in CR at the time of transplant ( 21.5 vs. $48 \%, p=0.009)$ and in patients who received PBSC as compared to BM (22 vs. $45 \%, p=0.009)$. In patients treated with SeqTh, 3-year OS was 19\%, while 3-year RI and NRM were 52 and $28 \%$ at a median follow-up of 50 months. Overall, Haplo-Tx was feasible in heavily pretreated high-risk patients without a suitable HLA-identical donor.
\end{abstract}

Keywords Allogeneic transplant $\cdot$ Haplo-identical $\cdot$ High-risk $\cdot$ Acute leukemias $\cdot$ Sequential therapy

* Benedetto Bruno benedetto.bruno@unito.it

${ }^{1}$ Department of Oncology, SSD Trapianto Allogenico, Presidio Molinette, AOU Città della Salute e della Scienza di Torino, Via Genova 3, 10126 Torino, Italy

${ }^{2}$ Department of Molecular Biotechnology and Health Sciences, University of Torino, Torino, Italy

${ }^{3}$ Division of Nuclear Medicine, AOU Città della Salute e della Scienza di Torino, Torino, Italy

${ }^{4}$ Department of Oncology, Division of Hematology, Presidio Molinette, AOU Città della Salute e della Scienza di Torino, Torino, Italy

${ }^{5}$ Department of Oncology, Division of Hematology Univ., Presidio Molinette, AOU Città della Salute e della Scienza di Torino, Torino, Italy

\section{Introduction}

Allografting is potentially curative for several hematological malignancies. Donor availability remains a major limitation. A HLA-identical sibling is currently considered the optimal donor at most centers. However, approximately only one third of the patients of Caucasian origin eventually find one in the family and $70 \%$ find a suitable unrelated donor. These figures are lower for individuals of ethnic minorities [1, 2]. Family haplo-identical donors and umbilical cord blood (UCB) units have become important alternatives for those patients without a suitable HLA-matched donor.

Haplo-identical hematopoietic stem cell transplantation (Haplo-Tx) is associated with intense bi-directional allo-reactivity. Different programs with both T-cell depleted (TCD) and T-cell repleted modalities were proposed over the decades to prevent graft vs. host disease (GVHD) while 
sparing the graft vs. leukemia effects. High rates of nonrelapse mortality (NRM) were however observed [3, 4]. More recently, other Haplo-Tx strategies were developed [5] either by refinements of T-cell depletion [6-8] or by intensified immune suppression [9-11]. The currently most commonly used T-cell replete (TCR) Haplo-Tx modality was pioneered by the Johns Hopkins group. In this setting, the administration of post-transplant cyclophosphamide (PT-Cy) plays a pivotal role [12-20]. Preclinical studies showed that PT-Cy targets allo-reactive T-cells generated early after Haplo-Tx, sparing non-dividing lymphocytes and hematopoietic stem cells mainly due to increased expression of protective aldehyde dehydrogenase (ALDH) [21-23]. In particular, Tregs resistance to cyclophosphamide was recently correlated with lower GVHD rates [24, 25].

At our center, the preferred alternative for patients who lack a HLA-identical sibling has been a HLA-matched or partially matched $(8 / 8$ or $7 / 8$ matched) unrelated donor. In 2010 , we implemented a Haplo-Tx program with PT-Cy for high-risk patients without a suitable donor. Here, we report our experience that helped to define our center policy.

\section{Patients and methods}

\section{Patients}

Seventy-one Haplo-Tx were performed in 70 patients with high-risk hematological malignancies at the Transplant Center of the Department of Oncology, Presidio Molinette, AOU Città della Salute e della Scienza di Torino, Torino, Italy, between January 2010 and January 2017. Fourteen patients, with shorter follow-up, were also part of a retrospective registry study by the European Bone Marrow Transplantation Group (EBMT) [26]. Patient and disease characteristics are summarized in Table 1. The hematopoietic cell transplantation comorbidity index (HCT-CI) was assessed as previously described [27]. Disease risk index (DRI) was calculated for patients who underwent Haplo-Tx as first transplant with the exception of 2 with rare diseases (blastic plasmocytoid dendritic cell neoplasm and plasmablastic lymphoma) [28]. All patients gave written informed consent to the proposed treatment and to the use of medical records for research purposes. The study was approved by the Center Ethical Committee and conducted according to the Declaration of Helsinki.

\section{Definition of haplo-identical donor}

HLA-typing was performed at high resolution level at HLAA, HLA-B, HLA-C, HLA-DRB1, and HLA-DQB1 loci. A haplo-identical donor was defined as a family donor with a shared haplotype and at least two HLA-mismatches at the allele level on the unshared haplotype [29].
Table 1 Patients and transplants characteristics

\begin{tabular}{ll}
\hline & $N(\%)$ \\
\hline Patients; Haplo-Tx & $70 ; 71$ \\
Median age, years (range) & $49(21-70)$ \\
Male & $36(51 \%)$ \\
Hematological disease & \\
AML & $47(67)$ \\
ALL-B, ALL-T & $9(13)$ \\
Aggressive NHL & $6(9)$ \\
MDS & $3(4)$ \\
CLL & $1(1)$ \\
CML-BC & $2(3)$ \\
BPDCN & $2(3)$ \\
Disease risk index (DRI) & \\
Intermediate & $34(48.5)$ \\
High/very high & $20(28.5)$ \\
Not applicable & $16(23)$ \\
2nd allogeneic transplant & \\
3rd allogeneic transplant & \\
Sequential therapy & $12(17)$ \\
HCT-CI $\geq 3$ 3 & $2(3)$ \\
Conditioning regimen & \\
Thiotepa + busulfan + fludarabine & $22(31)$ \\
Thiotepa + melphalan + fludarabine & $34(48)$ \\
Fludarabine + TBI 12 Gy & \\
Fludarabine + cyclophosphamide + TBI 2 Gy & $19(27)$ \\
Fludarabine + melphalan + TBI 2 Gy & $1(1)$ \\
Fludarabine & $1(1)$ \\
GVHD prophylaxis & \\
Tacrolimus + MMF + PT Cy 50 mg/kg +3/+4 & $66(93)$ \\
CSA + MMF + PT Cy 50 mg/kg +3/+5 & $4(7)$ \\
Stem cell source BM/PBSC \\
Median donor age, years (range) & $42(59) / 29(41)$ \\
\hline
\end{tabular}

Haplo-Tx haplo-identical transplant, $A M L$ acute myeloid leukemia, $A L L$ acute lymphoblastic leukemia, $N H L$ non-Hodgkin lymphoma, $M D S$ myelodysplastic syndromes, $C L L$ chronic lymphocytic leukemia, $C M L$ $B C$ chronic myeloid leukemia-blastic crisis, $B P D C N$ blastic plasmocytoid dendritic cell neoplasia, $H C T$-CI hematopoietic cell transplantation comorbidity index, TBI total body irradiation, $G V H D$ graft versus host disease, $M M F$ mycophenolate mofetil, $P T C y$ posttransplantation cyclophosphamide, CSA cyclosporine A, ATG antithymocyte globulin, $B M$ bone marrow, $P B S C$ peripheral blood stem cells

${ }^{a}$ Calculated for patients at 1 st Haplo-Tx

${ }^{\mathrm{b}}$ Calculated on 71 transplants

\section{Transplantation and graft vs. host disease} prophylaxis

Bone marrow (BM) was used as stem cell source in $42 / 71$ (59\%) transplants and granulocyte-colony stimulating factor (G-CSF) mobilized peripheral blood stem cells (PBSC) in 29/ $71(41 \%)$. Target cell doses were $\geq 3 \times 10^{8}$ total nucleated 
cells (TNCs) for BM and $\geq 5 \times 10^{6} \mathrm{CD} 34+$ cells $/ \mathrm{kg}$ for PBSC. Conditionings employed are illustrated in Table 1. GVHD prophylaxis consisted of PT-Cy $50 \mathrm{mg} / \mathrm{kg}$ on days +3 and + 4 , tacrolimus and mycophenolic acid (MMF) from day +5 in $66 / 71$ transplants (93\%). Four out of $71(6 \%)$ enrolled in a multicenter clinical trial received PT-Cy $50 \mathrm{mg} / \mathrm{kg}$ on days +3 and +5 plus, cyclosporine from day -1 and MMF from day + 1 as per protocol. MMF was stopped at days +35 and +28 , respectively. Tacrolimus and cyclosporine were tapered off by day +180 in the absence of GVHD. Acute and chronic GVHD were diagnosed according to standard criteria [30, 31].

\section{Supportive care and infection control}

All patients received daily G-CSF from the day after the second PT-Cy infusion until absolute neutrophil count (ANC) engraftment. During neutropenia, patients received prophylactic quinolones or cephalosporins. Antifungal prophylaxis included fluconazole in 11/71 (15\%) patients and echinocandins in 48/71 (66\%) (micafungin in 46/48, caspofungin in 2/48). Moreover, 12/71 $(17 \%)$ patients received secondary antifungal prophylaxis with mold-active triazoles (voriconazole in $6 / 12$, posaconazole in $3 /$ 12) or liposomal amphotericin-B (in 3/12). Long-term prophylaxis against herpes virus and Pneumocystis jirovecii was performed in all patients. Preemptive antiviral therapy was initiated when a cytomegalovirus (CMV) DNA viral load $\geq 10.000$ copies/ml by polymerase chain reaction assay was detected in peripheral blood. Diagnosis of invasive fungal infections (IFI) was defined according to the revised European Organization for Research and Treatment of Cancer/Mycoses Study Group (EORTC/MSG) definitions [32].

\section{Statistical analysis}

Primary end-points were overall survival (OS) and event-free survival (EFS). OS was defined as the time from transplant to death from any cause, while EFS as the time from transplant to progression/relapse/death from any cause, whichever occurred first. Alive patients were censored at the date of last contact (04/30/2017). Patients who received more than one transplant were censored as alive at the date of the second/ third transplant. Survival curves were estimated by the Kaplan-Meier method and compared using the log-rank test. The composite end point of GVHD-free/relapse-free survival (GRFS) after transplant was calculated as described by Holtan et al. [33]; OS and EFS were also analyzed by the Cox proportional hazards model, comparing the two arms by the Wald test and calculating $95 \%$ confidence intervals. The following covariates were tested as risk factors: donor age ( $\geq 40$ vs. $<$ 40 years), recipient age ( $\geq 40$ vs. $<40$ years), donor/recipient sex-mismatch (female into male vs. other), disease status at transplant (active disease vs. complete remission (CR), patients who received SeqTh were considered with active disease), time from diagnosis to transplant ( $>1$ vs. $\leq 1$ year), HCT-CI ( $\geq 3$ vs. $0-2$ ), stem cell source (bone marrow vs. peripheral blood), median cell doses infused/recipient weight $\left(\geq 7.3 \times 10^{6} \mathrm{CD} 34+/ \mathrm{kg}\right.$ vs. $<7.3 \times 10^{6} \mathrm{CD} 34+/ \mathrm{kg}$, or $\geq 4.6 \times$ $10^{8} \mathrm{TNC} / \mathrm{kg}$ vs. $<4.6 \times 10^{8} / \mathrm{kg} \mathrm{TNC} / \mathrm{kg}$ ), intensity of the conditioning (non-myeloablative/reduced intensity vs. myeloablative) [34],DRI. Cumulativeincidence(CI) analyses were calculated for the following events: acute GVHD [competing events (CE): relapse/death without acute GVHD); chronic GVHD (CE: relapse/death without chronic GVHD); NRM (CE: relapse), RI (CE: death without relapse), neutrophil (ANC) and platelet (PLT) engraftment by stem cell source (CE: death without engraftment), CMV reactivation (CE: death without $\mathrm{CMV}$ reactivation), and IFI occurrence (CE: relapse/death without IFI). CI was estimated by the Gray test and by the competing risks regression model comparing the risk factors by the Fine-Gray test [35, 36]. Patient characteristics were tested using the Fisher's exact test for categorical variables and the Mann-Whitney test for continuous ones. All results for continuous variables were expressed as median (range). All reported $p$ values were obtained by the two-sided exact method, at the conventional 5\% significance level. Data were analyzed as of May 2017 by R 3.2.3 (R Foundation for Statistical Computing, Vienna-A, http://www.R-project.org).

\section{Results}

\section{Donor selection and study population}

An unrelated donor search was initially started for $53 / 70 \mathrm{pa}-$ tients $(76 \%)$. Twenty-seven did not find a suitable donor while 18 (34\%) relapsed during the donor search and underwent Haplo-Tx. For 17/70 (24\%) patients, a donor search was not started because of age older than 65 years $(n=4)$, disease progression $(n=4)$, or graft failure $(n=1)$ after a first allograft from a sibling donor, very aggressive or refractory disease $(n=8)$ requiring an urgent transplant. Overall, 13 patients for a total of 14 transplants underwent Haplo-Tx as second or third allograft due to prior graft failure after Haplo-Tx ( $n=$ 1) or disease relapse after a previous allograft from UCB units, sibling, or unrelated donors $(n=12)$.

Median donor age was 38 years (range 16-66). Haploidentical donors were offspring in 34/71 (48\%) transplants, siblings in $21 / 71(30 \%)$, parents in $15 / 71(21 \%)$, and a first-degree cousin in 1/71 (1\%). Female donor into male recipient was used in 19/71 (27\%) transplants. Forty-seven/71 $(66 \%)$ recipient/donor pairs were fully allele-mismatched on the unshared haplotype, 15/71 (21\%) had 4 mismatches, and $9 / 71(13 \%) \leq 3$.

Thirty-one/70 (44\%) patients, including those who underwent SeqTh, had active disease at the time of transplant. HCT-CI was $\geq 3$ in $48 \%$. Median time from diagnosis to 
Haplo-Tx as first transplant ( $n=56)$ was 7.5 months (range 2.9-114 months).

\section{Cell doses and engraftment}

Median cell doses infused were $5.9 \times 10^{8} / \mathrm{kg}$ TNC (range $1.8-$ $20.0 \times 10^{8} / \mathrm{kg}$ ) and $7.3 \times 10^{6} \mathrm{CD} 34+/ \mathrm{kg}$ (range 4.1-15.5 $\times$ $10^{6} / \mathrm{kg}$ ) for BM and PBSC, respectively. No statistically significant differences were observed in CI of acute GVHD, chronic GVHD, ANC, and PLTS engraftment comparing patients who received graft with cell doses above or below the median. Median ANC recovery occurred on day +18 (range 14-24 days) for BM and on day + 15 (range 9-20 days) for PBSC $(p=0.001)$. Median PLTS recovery occurred on day + 27 (range 12-347) for BM and on day +21 (range 10-192) for PBSC $(p=0.004)$. CI of ANC recovery at day +30 were $97.6 \%$ for BM, and $86.2 \%$ for PBSC ( $p=0.535)$; CI of PLTS at days $+30,+60$, and +90 were $58.5,73.2$, and $78.9 \%$ for BM, and $69,72.4$, and $76 \%$ for $\operatorname{PBSC}(p=0.434)$.

\section{Acute and chronic GVHD}

Overall CI of acute grade II-IV GVHD was $45 \%$ at day +100 (Fig. 1a), whereas grade III-IV acute GVHD was $11 \%$ at day +100 . Median day of onset of acute GVHD was day 25 (range 7-100). CI of acute GVHD was significantly higher in patients who received PBSC versus BM (69 vs. $29 \%, p<$ 0.001). Day- 400 CI of overall chronic GVHD and moderatesevere chronic GVHD were 38.5 and 15\%, respectively (Fig. 1b); median day of onset was day +196 (range 104-340). Overall, chronic GVHD was mild, moderate, and severe in $12 / 20(60 \%), 4 / 20(20 \%)$, and $4 / 20(20 \%)$ of the evaluable patients. CI of overall chronic GVHD was $33.8 \%$ in patients who received PBSC and $38.2 \%$ in BM $(p=0.753)$. One-year GRFS of 56 patients who received Haplo-Tx as first allograft was $30.5 \%$ (Fig. 1c).

\section{Infections}

Median day of CMV reactivation was day +40 (range 23$152)$ in $38 / 70(54 \%)$ patients. Six/38 (15\%) had multiple CMV reactivations (range 2-4). No CMV disease occurred. $\mathrm{CI}$ of CMV reactivation was $53 \%$ at 3 months. Four/70 (6\%) showed Epstein-Barr virus (EBV) reactivation. Hemorragic cystitis developed in 12/70 (17\%) at a median of day +43 (range 31-102); BK viruria was detected in 10/12 (83\%). Overall, 15/70 (21\%) experienced IFI, probable in 14/15 and proven in 1/15. Proven IFI was caused by Aspergillus fumigatus and Aspergillus terreus detected by bronchoalveolar lavage culture. Median time of onset was day +73 (range 3-575). Breakthrough IFI was observed in $4 \%$ of the patients who received mold-active prophylaxis and $27 \%$ in those who received fluconazole. CI of probable-proven IFI was 20 and
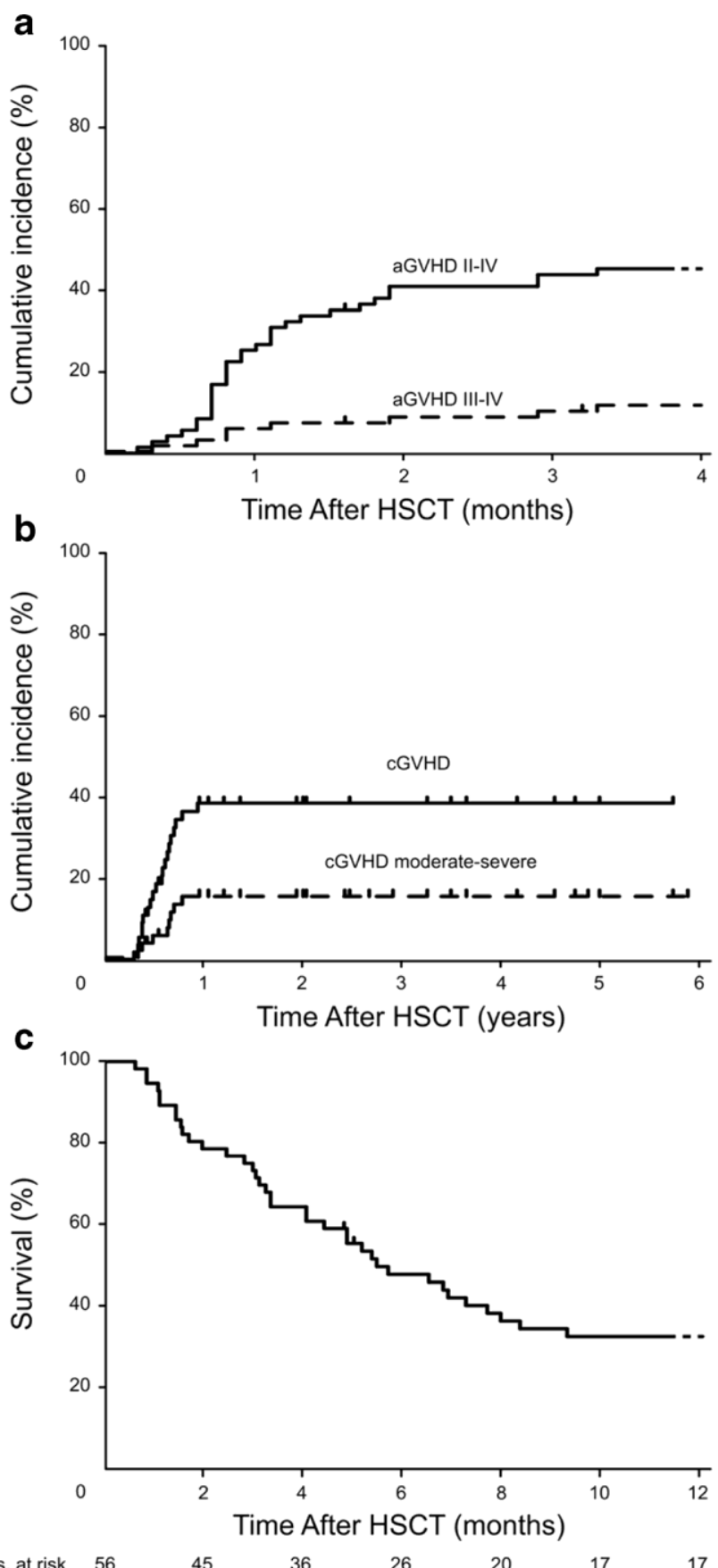

Fig. 1 a Cumulative Incidence of acute grade II-IV GVHD and grade IIIIV GVHD at day100 (71 transplants). b Cumulative Incidence of overall chronic GVHD and moderate-severe chronic GVHD at day400 (71 transplants). c BGVHD relapse-free survival^ ${ }^{\wedge}$ (GRFS) (56 patients who received Haplo-Tx as first allograft)

$22 \%$ at 12 and 24 months. By Gray test, the development of IFI was not influenced by age ( $p=0.051)$, acute grade II-IV GVHD (yes vs. no, $p=0.566$ ), acute grade III-IV GVHD (yes vs. no, $p=0.229$ ), and chronic GVHD (yes vs. no, $p=0.694$ ), conditioning regimen (non-myeloablative/reduced intensity vs. myeloablative, $p=0.839$ ), and stem cell source (BM vs. PBSC, $p=0.966$ ). 


\section{Clinical outcomes}

Median OS and EFS were 24 and 14.5 months (Fig. 2a). Thirty-four out of $70(48.5 \%)$ patients died. Median follow-up of survivors was 29.2 months (range 1.4-

71.2 months). Median follow-up was 42.2 months (range 1.4-71.2) and 23.7 months (range 3.2-59) for patients receiving BM and PBSC, respectively. Three-year OS and EFS were 43.8 and $40.2 \%$. For patients in CR $(n=40)$ at the time of Haplo-Tx, median OS and EFS were not reached at a follow-up of 29.2 months. Three-year OS was $54.6 \%$, 3-year EFS was $52.3 \%$ (Fig. 2c). No statistically significant differences in OS and EFS were observed in patients who received myeloablative vs. non-myeloablative/reduced intensity conditionings ( 53.5 vs. $48.0 \%, p=0.515$, and 42.4 vs. $35.9 \%, p=0.283$, at 2 years respectively), or PBSC vs. BM (60.3 vs. $47.5 \%, p=0.586$, and 55.3 vs. $32.7 \%, p=$ 0.257 , at 2 years, respectively). By univariate analysis, only DRI had a significant impact on OS (Table 2). A formal multivariate analysis was not performed given the sample size of our cohort.
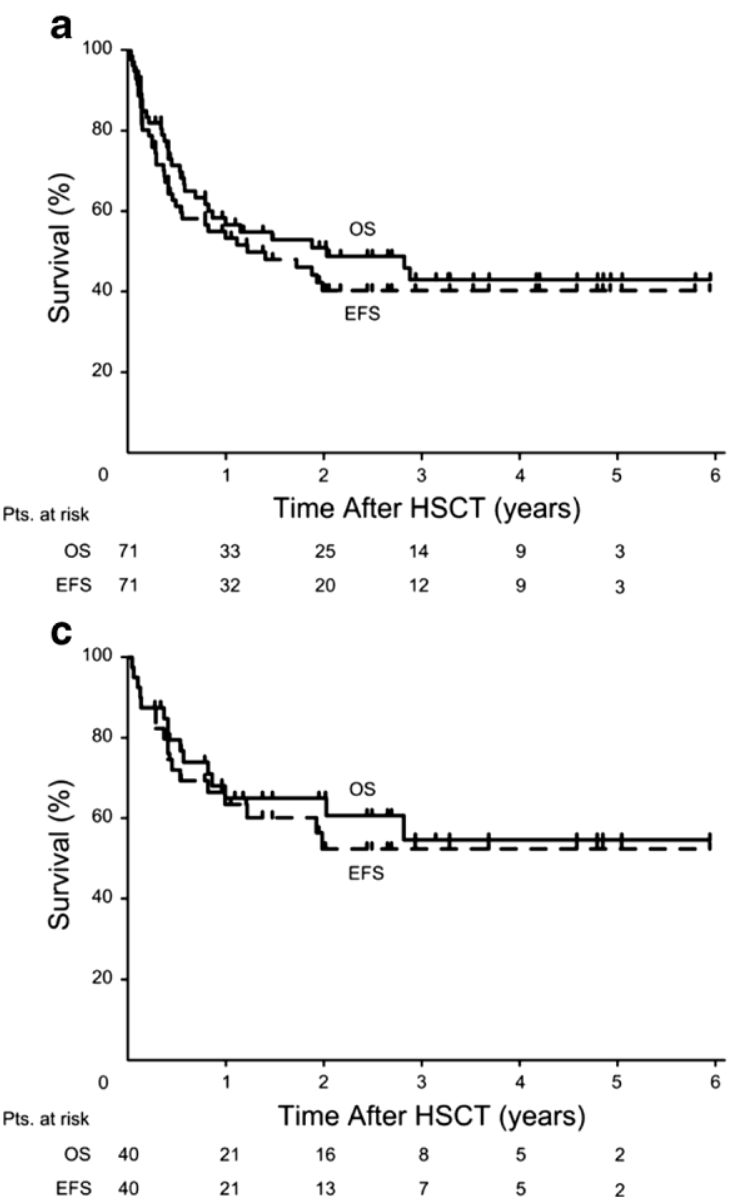

Fig. 2 a Overall survival (OS) and event-free survival (EFS) and b relapse incidence (RI) and non-relapse mortality (NRM) of the entire patient population (71 patients). C OS and EFS of 40 patients who were
CI of NRM was 25,27 , and $27 \%$ at 1,2 , and 3 years post-Haplo-Tx, respectively, whereas cumulative RI was 22, 33, and $33 \%$ at 1, 2, and 3 years (Fig. 2b). Three-year RI was significantly lower in patients in $\mathrm{CR}$ at the time of transplant $(21.5$ vs. $48 \%, p=0.009)$ and in patients who received PBSC as stem cell source (22 vs. $45 \%$, $p=0.009$ ).

\section{Sequential high-dose chemotherapy and haplo-identical transplant}

Overall, 22/70(31\%) high-risk patients were transplanted during the chemo-induced neutropenia after high-dose salvage chemotherapy (Table 3). Conditioning, myeloablative in 14/ $22(64 \%)$ and non-myeloablative in $8 / 22(36 \%)$, was started at a median of 9 days (range 4-15) after the last day of chemotherapy. Six/22 (27\%) had received a previous allograft. BM was used as stem cell source in 18/22 (82\%) patients. All patients but 2 , who presented with blast crisis of chronic myeloid leukemia, suffered from refractory $(n=12)$ or secondary $\operatorname{AML}(n=8)$. One/22 patients $(4 \%)$ experienced primary graft

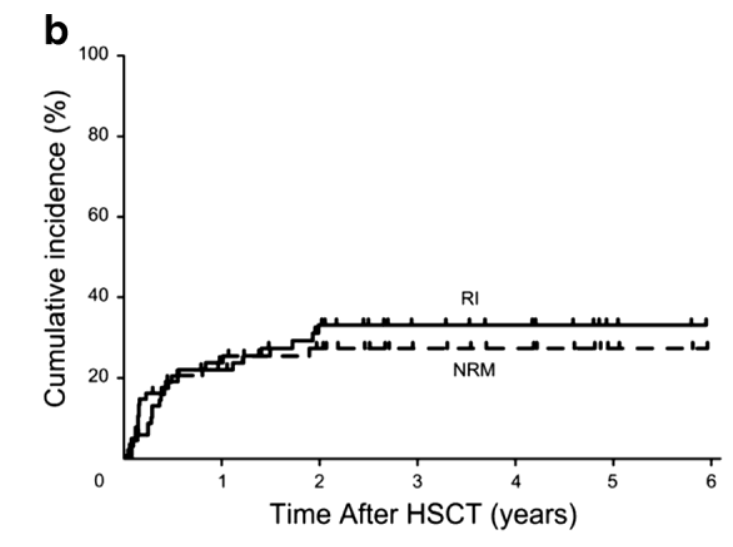

$\begin{array}{lllllll}\text { Pts. at risk } & 71 & 33 & 21 & 13 & 10 & 4\end{array}$

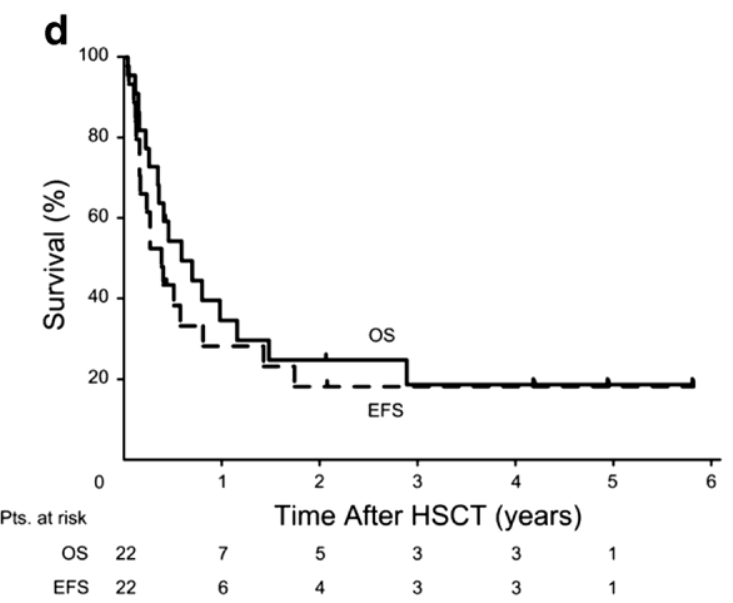

in complete remission at the time of Haplo-Tx. d OS and EFS of 22 patients who received sequential chemotherapy and allografting 


\begin{tabular}{|c|c|c|c|c|c|c|}
\hline & \multicolumn{3}{|l|}{ OS } & \multicolumn{3}{|l|}{ EFS } \\
\hline & HR & $95 \% \mathrm{CI}$ & $p$ & HR & $95 \% \mathrm{CI}$ & $p$ \\
\hline HCT-CI ( $\geq 3$ vs. $0-2$ ) & 1.01 & $0.50-2.04$ & 0.986 & 1.09 & $0.56-2.12$ & 0.805 \\
\hline $\begin{array}{l}\text { Conditioning regimen (myeloablative vs. } \\
\text { non-myeloablative) }\end{array}$ & 1.27 & $0.62-2.61$ & 0.517 & 1.44 & $0.74-2.8$ & 0.288 \\
\hline DRI (high/very high vs. intermediate) & 2.36 & $1.07-5.22$ & 0.034 & & & \\
\hline Donor/recipient sex match (F/M vs. other) & 1.21 & $0.58-2.53$ & 0.612 & 1.20 & $0.60-2.41$ & 0.614 \\
\hline Stem cell source (BM vs. PBSC) & 1.22 & $0.59-2.51$ & 0.587 & 1.48 & $0.75-2.91$ & 0.262 \\
\hline
\end{tabular}

OS overall survival, EFS event-free survival, $H R$ hazard ratio, $95 \%$ CI $95 \%$ confidence interval, $H C T$-CI hematopoietic cell transplantation comorbidity index, $D R I$ disease risk index, $F$ female, $M$ male, $P B S C$ peripheral blood stem cells, $B M$ bone marrow

failure and was successfully rescued with a second haploidentical transplant from the same donor. Median follow-up of survivors was 50 months (range 5-69 months); 3-year OS was $19 \%$ (Fig. 2d), while 3-year RI and NRM were 52 and $28 \%$, respectively. At day $+100 /+400$, CI of grade II-IV acute GVHD and chronic GVHD were 40.9 and 33.6\%, respectively (Table 4). A statistically significant difference in clinical outcomes was observed in patients who received myeloablative vs. non-myeloablative/reduced intensity conditionings (OS, $p=0.027$; EFS, $p=0.007$ ).

Table 3 Characteristics of patients undergoing sequential chemotherapy and allografting

\begin{tabular}{|c|c|c|c|c|c|c|c|c|c|}
\hline & Age & Sex & Status at Haplo HSCT & $\begin{array}{l}\text { Previous } \\
\text { Allo HSCT }\end{array}$ & Karyotype & $\begin{array}{l}\text { BM Blasts } \\
\text { at Seq. Th. }\end{array}$ & $\begin{array}{l}\text { Reinduction } \\
\text { regimen }\end{array}$ & Rest days & $\begin{array}{l}\text { Conditioning } \\
\text { regimen }\end{array}$ \\
\hline$\# 1$ & 58 & $\mathrm{~F}$ & Refractory sAML from RAEB1 & No & Monosomal & $25 \%$ & MEC & 9 & $\mathrm{TBF}$ \\
\hline$\# 2$ & 21 & $\mathrm{~F}$ & Refractory AML & Yes & $\operatorname{inv}(16),+8$ & $25 \%$ & AMSA+ARA-C & 4 & $\mathrm{FLU}+\mathrm{CY}+\mathrm{TBI}$ \\
\hline$\# 3$ & 40 & M & Refractory AML & Yes & Normal & $72 \%$ & AMSA+ARA-C & 10 & $\mathrm{FLU}+\mathrm{CY}+\mathrm{TBI}$ \\
\hline$\# 4$ & 37 & $\mathrm{~F}$ & Refractory AML & Yes & $11 \mathrm{q} 23$ mut & $17 \%$ & MEC & 4 & $\mathrm{FLU}+\mathrm{CY}+\mathrm{TBI}$ \\
\hline$\# 5$ & 34 & M & Refractory AML MDS related & No & $\mathrm{t}(3 ; 3)$ & $25 \%$ & MEC & 4 & $\mathrm{FLU}+\mathrm{CY}+\mathrm{TBI}$ \\
\hline \#6 & 50 & $\mathrm{~F}$ & Refractory sAML from CMML-2 & No & Normal & $43 \%$ & IDA+HD ARA-C* & 15 & $\mathrm{TBF}$ \\
\hline$\# 7$ & 54 & M & Refractory AML MDS related & No & Monosomal & $9 \%$ & MEC & 10 & TBF \\
\hline$\# 8$ & 42 & $\mathrm{~F}$ & Myeloid Blastic Crisis of CML & No & $\mathrm{t}(9 ; 22)$ & $34 \%$ & MEC & 9 & TBF \\
\hline$\# 9$ & 41 & $\mathrm{~F}$ & Refractory AML & Yes & Normal & $6 \%$ & CLOFA+ARA-C & 6 & $\mathrm{FLU}+\mathrm{CY}+\mathrm{TBI}$ \\
\hline$\# 10$ & 55 & M & Lymphoid Blastic Crisis of CML & No & $\mathrm{t}(9 ; 22)$ & $80 \%$ & HAM & 6 & TBF \\
\hline$\# 11$ & 29 & M & Refractory AML & No & +8 & $88 \%$ & $\mathrm{CLOFA}+\mathrm{ARA}-\mathrm{C}$ & 7 & $\mathrm{TBF}$ \\
\hline$\# 12$ & 62 & M & Refractory sAML & No & $-7 q$ & $32 \%$ & CLOFA+ARA-C & 8 & $\mathrm{TBF}$ \\
\hline$\# 13$ & 60 & $\mathrm{~F}$ & Refractory AML & No & Normal & $10 \%$ & MEC & 6 & $\mathrm{TBF}$ \\
\hline$\# 14$ & 46 & $\mathrm{~F}$ & Refractory AML & Yes & Normal & $21 \%$ & CLOFA+ARA-C & 9 & FLU+MEL+TBI \\
\hline \#15 & 53 & M & Refractory sAML from CNL & No & NA & $20 \%$ & MEC & 15 & $\mathrm{TBF}$ \\
\hline$\# 16$ & 51 & $\mathrm{~F}$ & Refractory AML Therapy-Related & No & Normal & $55 \%$ & MEC & 7 & TBF \\
\hline \#17 & 54 & $\mathrm{~F}$ & Refractory AML MDS related & No & Monosomal & $15 \%$ & IDA+HD ARA-C* & 12 & $\mathrm{TBF}$ \\
\hline \#18 & 48 & M & Refractory AML & No & $\operatorname{inv}(3)$ & $17 \%$ & CLOFA+ARA-C & 10 & TBF \\
\hline \#19 & 53 & $\mathrm{~F}$ & Refractory AML & No & Normal & $50 \%$ & MEC & 11 & $\mathrm{TBF}$ \\
\hline \#20 & 41 & M & Refractory AML & Yes & Complex & $15 \%$ & MEC & 11 & $\mathrm{FLU}+\mathrm{CY}+\mathrm{TBI}$ \\
\hline \#21 & 58 & M & Refractory AML & No & +21 & $75 \%$ & MEC & 11 & FLU+CY+TBI \\
\hline \#22 & 23 & M & Refractory AML & No & Normal & $52 \%$ & FAM & 11 & $\mathrm{TBF}$ \\
\hline
\end{tabular}

Reinduction regimens: MEC: mitoxantrone $6 \mathrm{mg} / \mathrm{sqm}$ day $1-4$, etoposide $80 \mathrm{mg} / \mathrm{sqm}$ day $1-4$, cytarabine $1 \mathrm{~g} / \mathrm{sqm}$ day $1-4$; AMSA+ARA-C: amsacrine $100 \mathrm{mg} / \mathrm{sqm}$ day $1-3$, cytarabine $2 \mathrm{~g} / \mathrm{sqm}$ day 1-3; IDA+HD ARA-C: idarubicin $17.5 \mathrm{mg} / \mathrm{sqm}$ day 3 and day 10 , cytarabine $3 \mathrm{~g} / \mathrm{sqm}$ BID day $1-2$ and day 8-9; CLOFA+ARA-C: clofarabine $40 \mathrm{mg} / \mathrm{sqm}$ day 1-4, cytarabine $1 \mathrm{~g} / \mathrm{sqm}$ day 1-4; HAM: cytarabine $3 \mathrm{~g} / \mathrm{sqm}$ BID day 1-3, mitoxantrone 10 mg/ sqm day 1-3, FAM: fludarabine $25 \mathrm{mg} / \mathrm{sqm}$ day $1-5$, cytarabine $2 \mathrm{~g} / \mathrm{sqm}$ day $1-5$, mitoxantrone $12 \mathrm{mg} / \mathrm{sqm}$ day 3-5

$A M L$ acute myeloid leukemia, $S A M L$ secondary AML, $R A E B 1$ refractory anemia with excess blasts-type $1, M D S$ myelodysplastic syndrome, $C M M L-2$ chronic myelomonocytic leukemia-type 2, CML chronic myeloid leukemia, $C N L$ chronic neutrophilic leukemia, $N A$ not available

*Cyclosporine A 12-h IV infusion days 3 and 10 
Table4 Outcome after sequential therapy approach

\begin{tabular}{llll}
\hline$N=22$ & 1 year & 2 years & 3 years \\
\hline Non-relapse mortality & $28 \%$ & $28 \%$ & $28 \%$ \\
Relapse incidence & $42 \%$ & $52 \%$ & $52 \%$ \\
Overall survival & $34.5 \%$ & $24.6 \%$ & $19 \%$ \\
Event-free survival & $30.3 \%$ & $20.2 \%$ & $20.2 \%$ \\
& & & \\
Grade II-IVacute GVHD & Day +100 & Day +400 & \\
Grade III-IV acute GVHD & $13.9 \%$ & & \\
Chronic GVHD & & & \\
Moderate/severe chronic GVHD & & $13.6 \%$ & \\
\hline
\end{tabular}

\section{Discussion}

The use of PT-Cy has allowed the rapid expansion of unmanipulated TCR Haplo-Tx [12-19]. In our series, most patients initially received $\mathrm{BM}$ and more recently $\mathrm{PBSC}$, given the high risk of relapse. ANC engraftment occurred on day +18 with $\mathrm{BM}$ and on day +15 with PBSC, while PLTS recovery occurred on day +27 with BM and on day +21 with PBSC and secondary failure of engraftment was mainly due to florid relapse [37]. Overall, life-threatening grade III-IV acute GVHD and moderate-severe chronic GVHD were 15 and $11 \%$. CI of acute GVHD was higher in patients who received PBSC versus $\mathrm{BM}$ while no difference in CI of chronic GVHD was observed. Differences in median follow-up between the two patient cohorts prevent however from drawing definitive conclusions. Of note, 1-year GRFS in patients who received Haplo-Tx as first allograft was $30.5 \%$ (Fig. 1c). This finding is particularly encouraging in heavily pretreated patients and is also a reliable surrogate of good quality of life. Overall, our findings are consistent with a larger EBMT registry study by Ruggeri et al. [26] where 451 patients with acute leukemias were analyzed. Use of PBSC rather than BM was significantly associated with increased risk of grade II-IV and III-IV acute GVHD while no differences were found in CI of chronic GVHD. A large US comparison on 681 patients with hematologic malignancy who underwent Haplo-Tx with PT-Cy and BM $(n=481)$ or PBSC $(n=190)$ grafts was also conducted [38]. Transplant outcomes were compared by graft type after adjusting for patient, disease, and transplant characteristics. ANC and PLTS engraftments were similar. Risk of grade II-IV and chronic GVHD was lower with BM as compared with PBSC. There were no differences in OS, with 2-year rates of 54 and $57 \%$ after BM and PBSC, respectively, and in NRM. Relapse risk was however higher after BM in patients with leukemia, but not with lymphoma. The authors conclude that both BM and PBSC grafts are suitable for Haplo-Tx though patterns of treatment failure differ.

Cell doses may play a role in clinical outcomes. In our study, CI of acute GVHD, chronic GVHD, neutrophil and
PLTS engraftment did not statistically differ between patients who received grafts with TNC and CD34+ cell doses above or below the infused median cell doses. Several reports focused on the impact of CD34+ cells on transplant outcomes with discordant results. After myeloablative conditionings and allografts from sibling donors, Przepiorka et al. reported that doses higher than $8.2 \times 10^{6} \mathrm{CD} 34+/ \mathrm{kg}$ correlated with increased risk of grade II-IV acute GVHD while Zaucha et al. reported an increased risk of chronic GVHD with doses higher than $8 \times 10^{6} \mathrm{CD} 34+/ \mathrm{kg}[39,40]$. By contrast, two registry studies from the National Marrow Donor Program (NMDP) and the Center for International Blood and Marrow Transplant Research (CIBMTR) showed that CD34+ cell doses respectively higher than $4.5 \times 10^{6}$ and $6 \times 10^{6} / \mathrm{kg}$ correlated with reduced NRM and improved OS [41, 42]. Recently, Czerw et al. reported that doses higher than $8.25 \times 10^{6} \mathrm{CD} 34+\mathrm{kg}$ were associated with increased risk of grade III-IV GVHD, but had no significant impact on NRM, leukemia relapse, incidence of chronic GVHD, and OS in leukemia patients undergoing reduced-intensity allografting from unrelated donors [43]. Discrepancies are probably due to different disease categories, disease status at transplant, donor type, intensity of the conditioning, and GVHD prophylaxis. No prospective dose finding study on the impact of cell doses/graft composition on clinical outcomes has so far been reported.

We observed viral reactivation but no life-threatening viral disease. CMV reactivated especially during the first 3 months post-transplant, but no CMV disease occurred [44]. Prospective monitoring of EBV DNA in blood is an institutional standard at our center while prophylaxis to prevent EBV reactivation is not given. Only $6 \%$ of our patients showed EBV reactivation. All patients remained asymptomatic and no post-transplant lymphoproliferative disorder was observed [45]. Hemorrhagic cystitis developed in $17 \%$ and most patients concomitantly showed BK viruria. Other viruses such as adenovirus and $\mathrm{JC}$ virus were not detected in the urine, and no major kidney complications were observed [46, 47]. Haplo-Tx patients are at high risk of developing IFI. Twenty-one percent of our patients developed fungal infections. Late infections were observed after mold-active primary prophylaxis had been stopped. A prospective evaluation of longer administration of mold active agents may be helpful.

Interestingly, $31 \%$ of our patients underwent a sequential approach—chemotherapy and allografting — to timely treat aggressive high-risk leukemia. Moreover, almost a third (6/ $22,27 \%$ ) had received a previous allograft. The sequential approach to treat myeloid malignancies was initially described by Schmid et al. [48-50]. In a prospective study, the combination of fludarabine, cytarabine, and amsacrine (FLAMSA) followed by reduced-intensity allografting from HLAmatched sibling or unrelated donors was associated with 2 year OS and 2-year EFS of 42 and $40 \%$ in 75 high-risk patients. More recently, Ringden et al. reported an outcome 
analysis on 267 patients with relapse/refractory AML who received sequential chemotherapy including fludarabine, cytarabine, and amsacrine followed by a reduced-intensity allograft from 77 HLA-matched siblings and from 190 HLA-matched unrelated donors [51]. Incidence of acute grade II-IV and chronic GHVD was 32.1 and $30.2 \%$, respectively. Three-year probability of NRM was $25.9 \%$, of relapse $48.5 \%$, of GRFS $17.8 \%$, and of leukemia-free survival $25.6 \%$. To our knowledge, we report on the largest experience of a sequential approach including Haplo-Tx. Outcomes of 30 refractory leukemia patients, where seven received intensive chemotherapy before Haplo-Tx, were described by Devillier et al. [52]. Overall and progression-free survivals were 37 and $32 \%$. Of the seven patients who received a sequential approach, two were alive in CR at 11 and 14 months after Haplo-Tx. Though our cohort is relatively small, at a median follow-up of 50 months, 3-year OS was $19 \%$. A survival advantage was seen with myeloablative conditionings. However, it is important to point out that some patients treated with nonmyeloablative/reduced intensity regimens had also received a prior allograft increasing the risk of toxicity. A formal comparison between matched sibling versus unrelated donor or haplo-identical donor transplants has not been reported in this setting. However, Schmid et al. [49] observed a reduced risk of death from leukemia with transplant from unrelated donors. However, given a higher risk of non-relapse mortality, this finding did not translate into better OS as compared with transplants from HLA-matched sibling donor.

In retrospective analyses, outcomes of Haplo HSCT with PT-Cy appeared similar to those reported after HLA-matched sibling or unrelated donor transplants [53-57]. However, results should be validated in prospective randomized trials to avoid the inevitable limitations of retrospective comparisons. When compared with UCB transplants, Haplo HSCT with PT-Cy also showed equal or even better results either in retrospective and parallel prospective studies [58, 59]. A large multicenter phase III randomized trial comparing double unit UCB versus Haplo-Tx is currently ongoing (ClinicalTrials. gov: NCT01597778). Our donor selection policy has not changed over the study period. Our Bhierarchical ${ }^{\wedge}$ selection includes first a HLA-identical sibling, second a fully or a 7/8 allele matched unrelated donor and third a haplo-identical family donor. Although Pidala et al. recently reported that only $5 \%$ of patients take longer than 59 days to find a suitable unrelated donor [60], an allograft may not be delayed especially in patients with refractory/relapsed malignancies. Atour center, during the study period, 114 allografts from HLAidentical siblings and 212 from unrelated donors were performed. We estimate that with the implementation of the Haplo-Tx program, 15-20\% of our patients who would not have found a suitable donor underwent a potentially curative allograft. However, our strategy by no means allows an unbiased comparison of clinical outcomes by donor type given the heterogeneity of patient cohorts and selection criteria. Thus, we strongly support the design of large multicenter prospective trials in the near future where clinical outcomes by donor type may reliably be compared and potential selection bias be reduced.

In summary, Haplo-Tx with PT-Cy is feasible in high-risk, heavily pretreated patients and can safely be part of a sequential Bchemotherapy and allografting ${ }^{\wedge}$ approach. Prospective comparisons of long-term clinical outcomes by different donor types are eagerly awaited.

Acknowledgments This work was partly supported by Progetti di Ricerca Finalizzata 2008-2009, Fondi di Ricerca Locale, Università degli Studi di Torino, Torino, Italy; by Fondazione Neoplasie Sangue (FO.NE. SA) ONLUS, Torino, Italy; and by Fondazione Cariplo (Grant per la Ricerca Biomedica 2015/0603 to B.B.). The authors would like to thank Maria Josè Fornaro and Sara Manetta for excellent secretarial support.

Author contributions B.B, A.B, and L.G designed the study. L.B., L.G., A.B., and B.B. wrote the report. L.G., A.B., and B.B. supervised the clinical conduction of the study and data analysis. B.B, A.B., C.D., and L.G. supervised data collection, analyzed data, and reviewed and assisted in writing the manuscript. A.B., B.B., C.D., S.A., B.A., L.G., and M.F. recruited the patients. R.P. did the statistical analysis.

\section{Compliance with ethical standards}

The study was approved by the Center Ethical Committee and conducted according to the Declaration of Helsinki.

Conflict of interest statement The authors declare that they have no conflict of interest.

\section{References}

1. Gragert L, Eapen M, Williams E, Freeman J, Spellman S, Baitty R, Hartzman R, Rizzo JD, Horowitz M, Confer D, Maiers M (2014) HLA match likelihoods for hematopoietic stem-cell grafts in the U. S. registry. NEngl J Med 371(4):339-348. https://doi.org/10.1056/ NEJMsa1311707

2. Ballen KK, King RJ, Chitphakdithai $P$ et al (2008) The national marrow donor program 20 years of unrelated donor hematopoietic cell transplantation. Biol Blood MarrowTransplant 14(9 Suppl):27. https://doi.org/10.1016/j.bbmt.2008.05.017

3. Aversa F, Terenzi A, Tabilio A, Falzetti F, Carotti A, Ballanti S, Felicini R, Falcinelli F, Velardi A, Ruggeri L, Aloisi T, Saab JP, Santucci A, Perruccio K, Martelli MP, Mecucci C, Reisner Y, Martelli MF (2005) Full haplotype-mismatched hematopoietic stem-cell transplantation: a phase II study in patients with acute leukemia at high risk of relapse. J Clin Oncol 23(15):3447-3454

4. Aversa F, Tabilio A, Velardi A, Cunningham I, Terenzi A, Falzetti F, Ruggeri L, Barbabietola G, Aristei C, Latini P, Reisner Y, Martelli MF, Felicini R, Falcinelli F, Carotti A, Perruccio K, Ballanti S, Santucci A, Gambelunghe C (1998) Treatment of high-risk acute leukemia with T-cell-depleted stem cells from related donors with one fully mismatched HLA haplotype. N Engl J Med 339(17): 1186-1193

5. Kanakry CG, Fuchs EJ, Luznik L (2016) Modern approaches to HLA-haploidentical blood or marrow transplantation. Nat Rev Clin Oncol 13(2):132. https://doi.org/10.1038/nrclinonc.2015.234. 
6. Martelli MF, Di Ianni M, Ruggeri L et al (2014) HLAhaploidentical transplantation with regulatory and conventional Tcell adoptive immunotherapy prevents acute leukemia relapse. Blood 124(4):638-644. https://doi.org/10.1182/blood-2014-03564401

7. Bertaina A, Merli P,Rutella S, Pagliara D, Bernardo ME, Masetti R, Pende D, Falco M, Handgretinger R, Moretta F, Lucarelli B, Brescia LP, Li Pira G, Testi M, Cancrini C, Kabbara N, Carsetti R, Finocchi A, Moretta A, Moretta L, Locatelli F (2014) HLAhaploidentical stem cell transplantation after removal of $\alpha \beta+T$ and $\mathrm{B}$ cells in children with nonmalignant disorders. Blood 124 (5):822-826. https://doi.org/10.1182/blood-2014-03-563817

8. Ciceri F, Bonini C, Stanghellini MTet al (2009) Infusion of suicidegene-engineered donor lymphocytes after family haploidentical haemopoietic stem-cell transplantation for leukaemia (the TK007 trial): a non-randomised phase I-II study. Lancet Oncol 10(5):489500. https://doi.org/10.1016/S1470-2045(09)70074-9

9. Lu DP, Dong L, Wu T, Huang XJ, Zhang MJ, Han W, Chen H, Liu DH, Gao ZY, Chen YH, Xu LP, Zhang YC, Ren HY, Li D, Liu KY (2006) Conditioning including antithymocyte globulin followed by unmanipulated HLA-mismatched/haploidenticalblood and marrow transplantation can achieve comparable outcomes with HLAidentical sibling transplantation. Blood 107(8):3065-3073

10. Wang Y, Liu QF, Xu LP, Liu KY, Zhang XH, Ma X, Fan ZP, Wu DP, Huang XJ (2015) Haploidentical vs identical-sibling transplant for AML in remission: a multicenter, prospective study. Blood 125 (25):3956-3962. https://doi.org/10.1182/blood-2015-02-627786

11. Di Bartolomeo P, Santarone S, De Angelis G et al (2013) Haploidentical, unmanipulated, G-CSF-primed bone marrow transplantation for patients with high-risk hematologic malignancies. Blood 121(5):849-857. https://doi.org/10.1182/blood-2012-08453399

12. O'Donnell PV, Luznik L, Jones RJ, Vogelsang GB, Leffell MS, Phelps M, Rhubart P, Cowan K, Piantadosi S, Fuchs EJ (2002) Non myeloablative bone marrow transplantation from partially HLA-mismatched related donors using post transplantation cyclophosphamide. Biol Blood Marrow Transplant 8(7):377-386

13. Luznik L, O'Donnell PV, Symons HJ, Chen AR, Leffell MS, Zahurak M, Gooley TA, Piantadosi S, Kaup M, Ambinder RF, Huff CA, Matsui W, Bolaños-Meade J, Borrello I, Powell JD, Harrington E, Warnock S, Flowers M, Brodsky RA, Sandmaier BM, Storb RF, Jones RJ, Fuchs EJ (2008) HLA-haploidentical bone marrow transplantation for hematologic malignancies using non myeloablative conditioning and high-dose, post transplantation cyclophosphamide. Biol Blood Marrow Transplant 14(6):641-650. https://doi.org/10.1016/j.bbmt.2008.03.005

14. McCurdy SR, Kanakry JA, Showel MM et al (2015) Risk-stratified outcomes of nonmyeloablative HLA-haploidentical BMT with high-dose post transplantation cyclophosphamide. Blood 125(19): 3024-3031. https://doi.org/10.1182/blood-2015-01-623991

15. Kasamon YL, Bolaños-Meade J, Prince GT, Tsai HL, McCurdy SR, Kanakry JA, Rosner GL, Brodsky RA, Perica K, Smith BD, Gladstone DE, Swinnen LJ, Showel MM, Matsui WH, Huff CA, Borrello I, Pratz KW, McDevitt MA, Gojo I, Dezern AE, Shanbhag S, Levis MJ, Luznik L, Ambinder RF, Fuchs EJ, Jones RJ (2015) Outcomes of nonmyeloablative HLA-haploidentical blood or marrow transplantation with high-dose post-transplantation cyclophosphamide in older adults. J Clin Oncol 33(28):3152-3161. https:// doi.org/10.1200/JCO.2014.60.4777

16. Solomon SR, Sizemore CA, Sanacore M, Zhang X, Brown S, Holland HK, Morris LE, Bashey A (2012) Haploidentical transplantation using $\mathrm{T}$ cell replete peripheral blood stem cells and myeloablative conditioning in patients with high-risk hematologic malignancies who lack conventional donors is well tolerated and produces excellent relapse-free survival: results of a prospective phase II trial. Biol Blood Marrow Transplant 18(12):1859-1866. https://doi.org/10.1016/j.bbmt.2012.06.019

17. Solomon SR, Sizemore CA, Sanacore M, Zhang X, Brown S, Holland HK, Morris LE, Bashey A (2015) Total body irradiationbased myeloablative haploidentical stem cell transplantation is a safe and effective alternative to unrelated donor transplantation in patients without matched sibling donors. Biol Blood Marrow Transplant 21(7):1299-1307. https://doi.org/10.1016/j.bbmt.2015. 03.003

18. Raiola AM, Dominietto A, Ghiso A, di Grazia C, Lamparelli T, Gualandi F, Bregante S, van Lint MT, Geroldi S, Luchetti S, Ballerini F, Miglino M, Varaldo R, Bacigalupo A (2013) Unmanipulated haploidentical bone marrow transplantation and post transplantation cyclophosphamide for hematologic malignancies after myeloablative conditioning. Biol Blood Marrow Transplant 19(1):117-122. https://doi.org/10.1016/j. bbmt.2012.08.014

19. Castagna L, Crocchiolo R, Furst S, Bramanti S, el Cheikh J, Sarina B, Granata A, Mauro E, Faucher C, Mohty B, Harbi S, Chabannon C, Carlo-Stella C, Santoro A, Blaise D (2014) Bone marrow compared with peripheral blood stem cells for haploidentical transplantation with a nonmyeloablative conditioning regimen and posttransplantation cyclophosphamide. Biol Blood Marrow Transplant. 20(5):724-729. https://doi.org/10.1016/j.bbmt.2014. 02.001

20. Raj K, Pagliuca A, Bradstock K, Noriega V, Potter V, Streetly M, Mclornan D, Kazmi M, Marsh J, Kwan J, Huang G, Getzendaner L, Lee S, Guthrie KA, Mufti GJ, O'Donnell P (2014) Peripheral blood hematopoietic stem cells for transplantation of hematological diseases from related, haploidentical donors after reduced-intensity conditioning. Biol Blood Marrow Transplant 20(6):890-895. https://doi.org/10.1016/j.bbmt.2014.03.003

21. Ross D, Jones M, Komanduri K, Levy RB (2013) Antigen and lymphopenia-driven donor $\mathrm{T}$ cells are differentially diminished by post-transplantation administration of cyclophosphamide after hematopoietic cell transplantation. Biol Blood Marrow Transplant 19 (10):1430-1438. https://doi.org/10.1016/j.bbmt.2013.06.019

22. Emadi A, Jones RJ, Brodsky RA (2009) Cyclophosphamide and cancer: golden anniversary. Nat Rev Clin Oncol 6(11):638-647. https://doi.org/10.1038/nrclinonc.2009.146

23. Kastan MB, Schlaffer E, Russo JE, Colvin OM, Civin CI, Hilton J (1990) Direct demonstration of elevated aldehyde dehydrogenase in human hematopoietic progenitor cells. Blood 75(10):1947-1950

24. Kanakry CG, Ganguly S, Zahurak M, Bolanos-Meade J, Thoburn C, Perkins B, Fuchs EJ, Jones RJ, Hess AD, Luznik L (2013) Aldehyde dehydrogenase expression drives human regulatory $\mathrm{T}$ cell resistance to post transplantation cyclophosphamide. Sci Transl Med 5(211):211ra157. https://doi.org/10.1126/scitranslmed. 3006960

25. Lussana F, Di Ianni M, Rambaldi A. (2017) Tregs: hype or hope for allogeneic hematopoietic stem cell transplantation? Bone Marrow Transplant. 2017 Mar 20. https://doi.org/10.1038/bmt.2017.30.

26. Ruggeri A, Labopin M, Bacigalupo A et al (2018) Bone marrow versus mobilized peripheralblood stemcells inhaploidentical transplants using posttransplantation cyclophosphamide. Cancer 124(7): 1428-1437

27. Sorror ML, Maris MB, Storb R, Baron F, Sandmaier BM, Maloney DG, Storer B (2005) Hematopoietic cell transplantation(HCT)-specific comorbidity index: a new tool for risk assessment before allogeneic HCT. Blood 106(8):2912-2919

28. Armand P, Gibson CJ, Cutler C, Ho VT, Koreth J, Alyea EP, Ritz J, Sorror ML, Lee SJ, Deeg HJ, Storer BE, Appelbaum FR, Antin JH, Soiffer RJ, Kim HT (2012) A disease risk index for patients undergoing allogeneic stem cell transplantation. Blood 120(4):905-913. https://doi.org/10.1182/blood-2012-03-418202 
29. Fuchs EJ (2015) HLA-haploidentical blood or marrow transplantation with high-dose, post-transplantation cyclophosphamide. Bone Marrow Transplant 50(Suppl 2):S31-S36. https://doi.org/10.1038/ bmt.2015.92

30. Filipovich AH, Weisdorf D, Pavletic S, Socie G, Wingard JR, Lee SJ, Martin P, Chien J, Przepiorka D, Couriel D, Cowen EW, Dinndorf P, Farrell A, Hartzman R, Henslee-Downey J, Jacobsohn D, McDonald G, Mittleman B, Rizzo JD, Robinson M, Schubert M, Schultz K, Shulman H, Turner M, Vogelsang G, Flowers MED (2005) National Institutes of Health consensus development project on criteria for clinical trials in chronic graftversus-host disease: I. Diagnosis and staging working group report. Biol Blood Marrow Transplant 11(12):945-956

31. Glucksberg H, Storb R, Fefer A et al (1974) Clinical manifestations of graft-versus-host disease in human recipients of marrow from HL-A-matched sibling donors. Transplantation 18(4):295-304

32. De Pauw B, Walsh TJ, Donnelly JP et al (2008) Revised definitions of invasive fungal disease from the European Organization for Research and Treatment of Cancer/Invasive Fungal Infections Cooperative Group and the National Institute of Allergy and Infectious Diseases Mycoses Study Group (EORTC/MSG) Consensus Group. Clin Infect Dis 46(12):1813-1821. https://doi. org/10.1086/588660

33. Holtan SG, DeFor TE, Lazaryan A et al (2015) Composite end point of graft-versus-host disease-free, relapse-free survival after allogeneic hematopoietic cell transplantation. Blood 125(8):13331338. https://doi.org/10.1182/blood-2014-10-609032

34. Bacigalupo A, Ballen K, Rizzo D, Giralt S, Lazarus H, Ho V, Apperley J, Slavin S, Pasquini M, Sandmaier BM, Barrett J, Blaise D, Lowski R, Horowitz M (2009) Defining the intensity of conditioning regimens: working definitions. Biol Blood Marrow Transplant 15(12):1628-1633. https://doi.org/10.1016/j.bbmt. 2009.07.004

35. Gray RJ (1988) A class of K-sample tests for comparing the cumulative incidence of a competing risk. Ann Stat 16:1141-1154

36. Fine JP, Gray RJ (1999) A proportional hazards model for the subdistribution of a competing risk. J Am Stat Assoc 94:496-509

37. Bruno B, Gooley T, Sullivan KM, Davis C, Bensinger WI, Storb R, Nash RA (2001) Secondary failure of platelet recovery after hematopoietic stem cell transplantation. Biol Blood Marrow Transplant 7 (3):154-162

38. Bashey A, Zhang MJ, McCurdy SR et al (2017) Mobilized peripheral blood stem cells versus unstimulated bone marrow as a graft source for T-cell-replete haploidentical donor transplantation using post-transplant cyclophosphamide. J Clin Oncol. https://doi.org/10. 1200/JCO.2017.72.8428

39. Przepiorka D, Smith TL, Folloder J, Khouri I, Ueno NT, Mehra R, Körbling M, Huh YO, Giralt S, Gajewski J, Donato M, Cleary K, Claxton D, Braunschweig I, van Besien K, Andersson BS, Anderlini P, Champlin R (1999) Risk factors for acute graftversus-host disease after allogeneic blood stem cell transplantation. Blood 94(4):1465-1470

40. Zaucha JM, Gooley T, Bensinger WI, Heimfeld S, Chauncey TR, Zaucha R, Martin PJ, Flowers ME, Storek J, Georges G, Storb R, Torok-Storb B (2001) CD34 cell dose in granulocyte colonystimulating factor-mobilized peripheral blood mononuclear cell grafts affects engraftment kinetics and development of extensive chronic graft-versus-host disease after human leukocyte antigenidentical sibling transplantation. Blood 98(12):3221-3227

41. Pulsipher MA, Chitphakdithai P,Logan BR, Leitman SF, Anderlini P, Klein JP, Horowitz MM, Miller JP, King RJ, Confer DL (2009) Donor, recipient, and transplant characteristics as risk factors after unrelated donor PBSC transplantation: beneficial effects of higher CD34+ cell dose. Blood 114(13):2606-2616. https://doi.org/10. 1182/blood-2009-03-208355
42. Törlén J, Ringdén O, Le Rademacher J et al (2014) Low CD34 dose is associated with poor survival after reduced-intensity conditioning allogeneic transplantation for acute myeloid leukemia and myelodysplastic syndrome. Biol Blood Marrow Transplant 20(9): 1418-1425. https://doi.org/10.1016/j.bbmt.2014.05.021

43. Czerw T, Labopin M, Schmid C, Cornelissen JJ, Chevallier P, Blaise D, Kuball J, Vigouroux S, Garban F, Lioure B, Fegueux N, Clement L, Sandstedt A, Maertens J, Guillerm G, Bordessoule D, Mohty M, Nagler A (2016) High CD3+ and CD34+ peripheral blood stem cell grafts content is associated with increased risk of graft-versus-host disease without beneficial effect on disease control after reduced-intensity conditioning allogeneic transplantation from matched unrelated donors for acute myeloid leukemia - an analysis from the Acute Leukemia Working Party of the European Society for Blood and Marrow Transplantation. Oncotarget 7(19):27255-27266. https://doi.org/10.18632/ oncotarget.8463.

44. Crocchiolo R, Bramanti S, Vai A, Sarina B, Mineri R, Casari E, Tordato F, Mauro E, Timofeeva I, Lugli E, Mavilio D, Carlo-Stella C, Santoro A, Castagna L (2015) Infections after T-replete haploidentical transplantation and high-dose cyclophosphamide as graft-versus-host disease prophylaxis. Transpl Infect Dis 17(2): 242-249. https://doi.org/10.1111/tid.12365

45. Kanakry JA, Kasamon YL, Bolaños-Meade J, Borrello IM, Brodsky RA, Fuchs EJ, Ghosh N, Gladstone DE, Gocke CD, Huff CA, Kanakry CG, Luznik L, Matsui W, Mogri HJ, Swinnen LJ, Symons HJ, Jones RJ, Ambinder RF (2013) Absence of posttransplantation lymphoproliferative disorder after allogeneic blood or marrow transplantation using post-transplantation cyclophosphamide as graft-versus-host disease prophylaxis. Biol Blood Marrow Transplant 19(10):1514-1517. https://doi.org/10.1016/j. bbmt.2013.07.013

46. Bruno B, Gooley T, Hackman RC, Davis C, Corey L, Boeckh M (2003) Adenovirus infection in hematopoietic stem cell transplantation: effect of ganciclovir and impact on survival. Biol Blood Marrow Transplant 9(5):341-352

47. Bruno B, Zager RA, Boeckh MJ, Gooley TA, Myerson DH, Huang ML, Hackman RC (2004) Adenovirus nephritis in hematopoietic stem-cell transplantation. Transplantation 77(7):1049-1057

48. Schmid C, Schleuning M, Ledderose G, Tischer J, Kolb HJ (2005) Sequential regimen of chemotherapy, reduced-intensity conditioning for allogeneic stem-cell transplantation, and prophylactic donor lymphocyte transfusion in high-risk acute myeloid leukemia and myelodysplastic syndrome. J Clin Oncol 23(24):5675-5687

49. Schmid C, Schleuning M, Schwerdtfeger R, Hertenstein B, Mischak-Weissinger E, Bunjes D, Harsdorf SV, Scheid C, Holtick U, Greinix H, Keil F, Schneider B, Sandherr M, Bug G, Tischer J, Ledderose G, Hallek M, Hiddemann W, Kolb HJ (2006) Long-term survival in refractory acute myeloidleukemia after sequential treatment with chemotherapy and reduced-intensity conditioning for allogeneic stem cell transplantation. Blood 108(3):1092-1099

50. Schneidawind D, Federmann B, Faul C, Vogel W, Kanz L, Bethge WA (2013) Allogeneic hematopoietic cell transplantation with reduced-intensity conditioning following FLAMSA for primary refractory or relapsed acute myeloid leukemia. Ann Hematol 92(10): 1389-1395. https://doi.org/10.1007/s00277-013-1774-5

51. Ringdén O, Labopin M, Schmid C, Sadeghi B, Polge E, Tischer J, Ganser A, Michallet M, Kanz L, Schwerdtfeger R, Nagler A, Mohty M, the Acute Leukaemia Working Party of the EBMT (2017) Sequential chemotherapy followed by reduced-intensity conditioning and allogeneic haematopoietic stem cell transplantation in adult patients with relapse or refractory acute myeloid leukaemia: a survey from the Acute Leukaemia Working Party of EBMT. Br J Haematol 176(3):431-439. https://doi.org/10.1111/ bjh. 14428 
52. Devillier R, Bramanti S, Fürst S, Sarina B, el-Cheikh J, Crocchiolo R, Granata A, Chabannon C, Morabito L, Harbi S, Faucher C, Santoro A, Weiller PJ, Vey N, Carlo-Stella C, Castagna L, Blaise D (2016) T-replete haploidentical allogeneic transplantation using post-transplantation cyclophosphamide in advanced AML and myelodysplastic syndromes. Bone Marrow Transplant 51(2):194198. https://doi.org/10.1038/bmt.2015.270

53. Burroughs LM, O'Donnell PV, Sandmaier BM, Storer BE, Luznik L, Symons HJ, Jones RJ, Ambinder RF, Maris MB, Blume KG, Niederwieser DW, Bruno B, Maziarz RT, Pulsipher MA, Petersen FB, Storb R, Fuchs EJ, Maloney DG (2008) Comparison of outcomes of HLA-matched related, unrelated, or HLA-haploidentical related hematopoietic cell transplantation following nonmyeloablative conditioning for relapsed or refractory Hodgkin lymphoma. Biol Blood Marrow Transplant 14(11):1279-1287. https://doi.org/10.1016/j.bbmt.2008.08.014

54. Raiola AM, Dominietto A, Di Grazia C et al (2014) Unmanipulated haploidentical transplants compared with other alternative donors and matched sibling grafts. Biol Blood Marrow Transplant 20(10): 1573-1579. https://doi.org/10.1016/j.bbmt.2014.05.029

55. Di Stasi A, Milton DR, Poon LM et al (2014) Similar transplantation outcomes for acute myeloid leukemia and myelodysplastic syndrome patients with haploidentical versus 10/10 human leukocyte antigen-matched unrelated and related donors. Biol Blood Marrow Transplant 20(12):1975-1981. https://doi.org/10.1016/j. bbmt.2014.08.013

56. Ciurea SO, Zhang MJ, Bacigalupo A et al (2015) Haploidentical transplant with posttransplant cyclophosphamide vs matched unrelated donor transplant for acute myeloid leukemia. Blood 126 (8):1033-1040. https://doi.org/10.1182/blood-2015-04-639831

57. Bashey A, Zhang X, Sizemore CA, Manion K, Brown S, Holland HK, Morris LE, Solomon SR (2013) T-cell-replete HLAhaploidentical hematopoietic transplantation for hematologic malignancies using post-transplantation cyclophosphamide results in outcomes equivalent to those of contemporaneous HLA-matched related and unrelated donor transplantation. J Clin Oncol 31(10): 1310-1316. https://doi.org/10.1200/JCO.2012.44.3523

58. Ruggeri A, Labopin M, Sanz G et al (2015) Comparison of outcomes after unrelated cordblood and unmanipulated haploidentical stem cell transplantation in adults with acute leukemia. Leukemia 29(9):1891-1900. https://doi.org/10.1038/leu.2015.98

59. Brunstein CG, Fuchs EJ, Carter SL, Karanes C, Costa LJ, Wu J, Devine SM, Wingard JR, Aljitawi OS, Cutler CS, Jagasia MH, Ballen KK, Eapen M, O'Donnell PV, on behalf of the Blood and Marrow Transplant Clinical Trials Network (2011) Alternative donor transplantation after reduced intensity conditioning: results of parallel phase 2 trials using partially HLA-mismatched related bone marrow or unrelated double umbilical cord blood grafts. Blood 118 (2):282-288. https://doi.org/10.1182/blood-2011-03-344853

60. Pidala J, Kim J, Schell M, Lee SJ, Hillgruber R, Nye V, Ayala E, Alsina M, Betts B, Bookout R, Fernandez HF, Field T, Locke FL, Nishihori T, Ochoa JL, Perez L, Perkins J, Shapiro J, Tate C, Tomblyn M, Anasetti C (2013) Race/ethnicity affects the probability of finding an HLA-A, -B, -C and -DRB1 allele-matched unrelated donor and likelihood of subsequent transplant utilization. Bone Marrow Transplant 48(3):346-350. https://doi.org/10.1038/ bmt.2012.150 